\title{
Harmless effects of argon plasma on caudal fin regeneration and embryogenesis of zebrafish: novel biological approaches for safe medical applications of bioplasma
}

\author{
Min-Kyung Nam ${ }^{1,2,5}$, Goo-Young Kim ${ }^{1,2,5}$, Si-Eun Yun ${ }^{1,2}$, Ja-Young Jang ${ }^{3}$, Yong-Hee Kim ${ }^{4}$, Eun Ha Choi ${ }^{4}$, \\ Seongman Kang $^{3}$ and Hyangshuk Rhim ${ }^{1,2}$
}

The argon plasma jet (Ar-PJ) is widely used in medical fields such as dermatology and dentistry, and it is considered a promising tool for cancer therapy. However, the in vivo effects of Ar-PJ for medical uses have not yet been investigated, and there are no biological tools to determine the appropriate clinical dosages of Ar-PJ. In this study, we used the caudal fin and embryo of zebrafish as novel in vivo tools to evaluate the biosafety of Ar-PJ. Typically, Ar-PJ is known to induce cell death in twodimensional (2D) cell culture systems. By contrast, no detrimental effects of Ar-PJ were shown in our 3D zebrafish systems composed of 2D cells. The Ar-PJ-treated caudal fins grew by an average length of $0.7 \mathrm{~mm}$, similar to the length of the normally regenerating fins. Remarkably, Ar-PJ did not affect the expression patterns of Wnt8a and $\beta$-Catenin, which play important roles in fin regeneration. In the embryo system, $85 \%$ of the Ar-PJ-treated embryos hatched, and the lateral length of these embryos was $\sim 3.3 \mathrm{~mm}$, which are equivalent to the lengths of normal embryos. In particular, vasculogenesis, which is the main cellular process during tissue regeneration and embryogenesis, occurred normally under the Ar-PJ dose used in this study. Therefore, our biosafety evaluation tools that use living model systems can be used to provide an experimental guideline to determine the clinically safe dosage of Ar-PJ.

Experimental \& Molecular Medicine (2017) 49, e355; doi:10.1038/emm.2017.95; published online 14 July 2017

\section{INTRODUCTION}

Nonthermal atmospheric argon (Ar) plasma has several distinct advantages that are applicable to medical use. ${ }^{1,2}$ First, noble gases are safe for human use because they are typically highly unreactive. Second, the noble gas Ar is required to ensure the stability of plasma $\left(\mathrm{Ar}^{+}+\mathrm{e}^{-} \rightarrow \mathrm{Ar}\right)$. Third, Ar is less expensive than other noble gases because it is the third most abundant gas in the Earth's atmosphere, after nitrogen and oxygen. Fourth, Ar plasma contains less ozone, which is harmful to living organisms, than do other gas plasmas. ${ }^{3}$ Nonthermal Ar plasma has also been demonstrated to be biocompatible because of its capacity to generate low-temperature, highly reactive species, including reactive oxygen species (ROS), and the easy control of its plasma dynamics. ${ }^{4,5}$
ROS have dual functions in many essential cellular processes. $^{6-8}$ At low or physiological levels, ROS serve as critical signaling molecules in cellular proliferation and survival, ${ }^{8,9}$ whereas at high or super-physiological levels, ROS can induce damage in the components of living organisms. ${ }^{10-14}$ These intriguing features of ROS may make Ar plasma one of the most promising approaches for applications in medical fields. ${ }^{15-17}$ Emerging evidence suggests that Ar plasma can be used as a new tool in the removal of cancerous tissues via the efficient and preferential killing of cancer cells. ${ }^{18-21}$ However, programmed cell death can be applicable to cancer therapy, whereas other types of cell death, such as necrosis, may cause detrimental tissue damage through the uncontrolled release of inflammatory molecules into the extracellular space., ${ }^{7,22-24}$

\footnotetext{
${ }^{1}$ Department of Biomedicine and Health Sciences, College of Medicine, The Catholic University of Korea, Seoul, Republic of Korea; ${ }^{2}$ Department of Medical Life Sciences, College of Medicine, The Catholic University of Korea, Seoul, Republic of Korea; ${ }^{3}$ Division of Life Sciences, College of Life Sciences and Biotechnology, Korea University, Seoul, Republic of Korea and ${ }^{4}$ Plasma Bioscience Research Center, Kwangwoon University, Seoul, Republic of Korea ${ }^{5}$ These authors contributed equally to this work.

Correspondence: Dr M-K Nam or Professor H Rhim, Department of Medical Life Sciences, College of Medicine, The Catholic University of Korea, 222 Banpo-daero, Seocho-gu, Seoul 137-701, Republic of Korea.
}

E-mail: wangmouse@catholic.ac.kr or hrhim@catholic.ac.kr

Received 2 December 2016; revised 8 February 2017; accepted 14 February 2017 
Moreover, many studies have reported that Ar plasma induces cancer cell death in two-dimensional (2D) culture

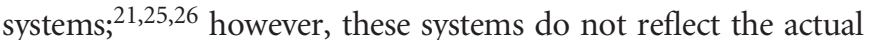
cellular environment of organisms due to the absence of cell-to-cell communication in tissue-specific architectures. Hence, before applying Ar plasma in the medical field, standard protocols must be established with appropriate living models to monitor and evaluate both the biosafety of Ar plasma and the appropriate dosage for clinical use.

The fibroblast growth factor (FGF)- and wingless-type MMTV integration site family (Wnt)/ $\beta$-Catenin-signaling pathways play important roles in the formation of progenitor cells and the regulation of regeneration. ${ }^{27}$ These two pathways are highly conserved between zebrafish and humans. Moreover, FGF20a and Wnt8a are essential for initiating regeneration and were first identified in zebrafish. ${ }^{27-29}$ These epigenetic and molecular studies have experimentally confirmed that zebrafish model systems can provide invaluable information for understanding the cellular events and reactions that occur in human tissues.

In this study, we have establish new strategies and protocols to monitor and evaluate the biosafety of the Ar plasma jet (Ar-PJ) by analyzing the regenerative capacity of the zebrafish caudal fin and embryonic development. On the basis of these in vivo zebrafish systems, we demonstrate that Ar-PJ is safe in living organisms at widely applied doses in medical fields. Furthermore, our system can become a useful, reliable, and critical tool for evaluating Ar-PJ biosafety for human use and provides insights into future directions for developing next-generation cancer therapies.

\section{MATERIALS AND METHODS}

\section{Zebrafish maintenance}

Adult wild-type zebrafish (Danio rerio, 5-10 months old) were raised under standard laboratory conditions described in a laboratory manual of zebrafish. Zebrafish embryos were obtained by natural mating after the initiation of the light cycle and were raised under standard laboratory conditions at $28.5^{\circ} \mathrm{C}$ for subsequent experimental procedures. Developmental stages were assigned in accordance with the morphological criteria defined by Kimmel et al. The animal experiments were approved by the Institutional Animal Care and Use Committees at the College of Medicine, the Catholic University of Korea (IACUC No.: CUMC-2010-0206-01).

\footnotetext{
Nonthermal argon plasma jet device

The nonthermal argon plasma jet (Ar-PJ) system consists primarily of inner and outer electrodes, porous alumina with dielectric properties and an alternating current (AC) high-voltage power supply, which is a commercially available transformer operated at $60 \mathrm{~Hz}$ (hertz). Ar gas was injected into the hollow space of the injection needle at a flow rate of 0.5 SLM (standard liters per minute) and ejected through the hole in the outer electrode via the porous alumina. Once Ar gas and $100 \mathrm{~V}$ AC were applied, the discharge was fired in the porous alumina between the electrodes; thus, Ar-PJ was generated and ejected through the hole in the outer electrode. For indirect plasma treatment, a grounded mesh was placed between the high voltage electrode and the sample to eliminate charged particles.
}

\section{Ar-PJ treatment}

The live embryos at $3.3 \mathrm{hpf}$ were lined up on a Petri dish and treated with the indicated doses of Ar-PJ. The zebrafish embryos were incubated at $28.5^{\circ} \mathrm{C}$ and analyzed at 19 and $60 \mathrm{hpf}$. Adult zebrafish were anesthetized in $0.016 \%$ ethyl 3-aminobenzoate methanesulfonate (tricane; Sigma Chemical, St Louis, MO, USA), and their caudal fins were amputated at the mid-fin level using a surgical blade. Following amputation, zebrafish were transferred to a Petri dish, and the fins were spaced at approximately $2 \mathrm{~mm}$ apart from the Ar-PJ device and treated with the indicated doses of Ar-PJ for $30 \mathrm{~s}$. Following the treatments, the adult zebrafish were maintained at $33^{\circ} \mathrm{C}$, which is an optimal temperature to accelerate the regenerative process. After 2 and $4 \mathrm{dpa}$, zebrafish were anesthetized and collected for further analysis.

\section{Whole-mount in situ hybridization (WISH)}

Adult zebrafish caudal fins and embryos were fixed in $4 \%$ paraformaldehyde for $18 \mathrm{~h}$ at $4{ }^{\circ} \mathrm{C}$. Antisense digoxigenin (DIG)-labeled RNA probes (wnt8a and fli-1) were synthesized by in vitro transcription using T7 RNA polymerase (Takara Biotechnology, Shiga, Japan) with a DIG-RNA Labeling Mix according to the manufacturer's instruction (Roche Diagnostics, Basel, Switzerland). WISH was performed using the method described in the Zebrafish Book, and the target mRNAs were visualized by anti-DIG Fab fragments conjugated with alkaline phosphatase and NBT/BCIP system (Roche). The plasmids used to transcribe antisense riboprobes, wnt $8 a$ and $f l i-1$, were provided by the Korea Zebrafish Organogenesis Mutant Bank (ZOMB) and Dr Cheol-Hee Kim (Chungnam National University), respectively.

\section{Immunofluorescence assay}

Immunofluorescence assay (IFA) was performed using the method described in The Zebrafish Book. The fixed fins were incubated with the mouse anti-active- $\beta$-Catenin (Millipore, Billerica, MA, 05-665, $1: 200)$ for $18 \mathrm{~h}$ at $4{ }^{\circ} \mathrm{C}$ and incubated with goat anti-mouse Alexa Fluor 488 (Molecular probe, Eugene, OR, USA; A 11001, 1:200) for $2 \mathrm{~h}$. The samples were counterstained with $2 \mu \mathrm{g} \mathrm{ml}^{-1} 4^{\prime}, 6$-diamidino2-phenylindole (DAPI, nuclear marker) for $10 \mathrm{~min}$. The samples that were prepared for IFA were analyzed by confocal microscopy (Carl Zeiss, Oberkochen, Germany).

\section{Image analyses and statistical analyses}

Live and WISH embryos were mounted in 3\% methylcellulose and $80 \%$ glycerol in egg water $(0.6 \mathrm{~g}$ aquarium salt and $0.01 \mathrm{mg}$ methylene blue in 1 liter distilled water). The processed caudal fins were mounted using glass slides and cover slips. The images were visualized using a dissection microscope (Leica MZFLIII, Heidelberg, Germany) and a camera system (Leica DFC 490 and Leica Application Suite ver. 2.8.1). Levels of statistical significance were assessed by Student's $t$-tests using SigmaPlot (version 9.0). All data are presented as the mean \pm s.e.m.

\section{RESULTS}

Ar plasma induces cell death in the $2 \mathrm{D}$ culture system: implications for the in vivo biosafety evaluation of plasma for medical applications

In the bioplasma research field, standard monolayer cell culture has been widely used as the $2 \mathrm{D}$ culture system for evaluating cellular responses to Ar plasma. ${ }^{19,21,25,30}$ Mouse embryonic fibroblast (MEF) cells were used as the 2D monolayer culture system because fibroblasts are the most common cells of connective tissue in animals, and their morphological features 


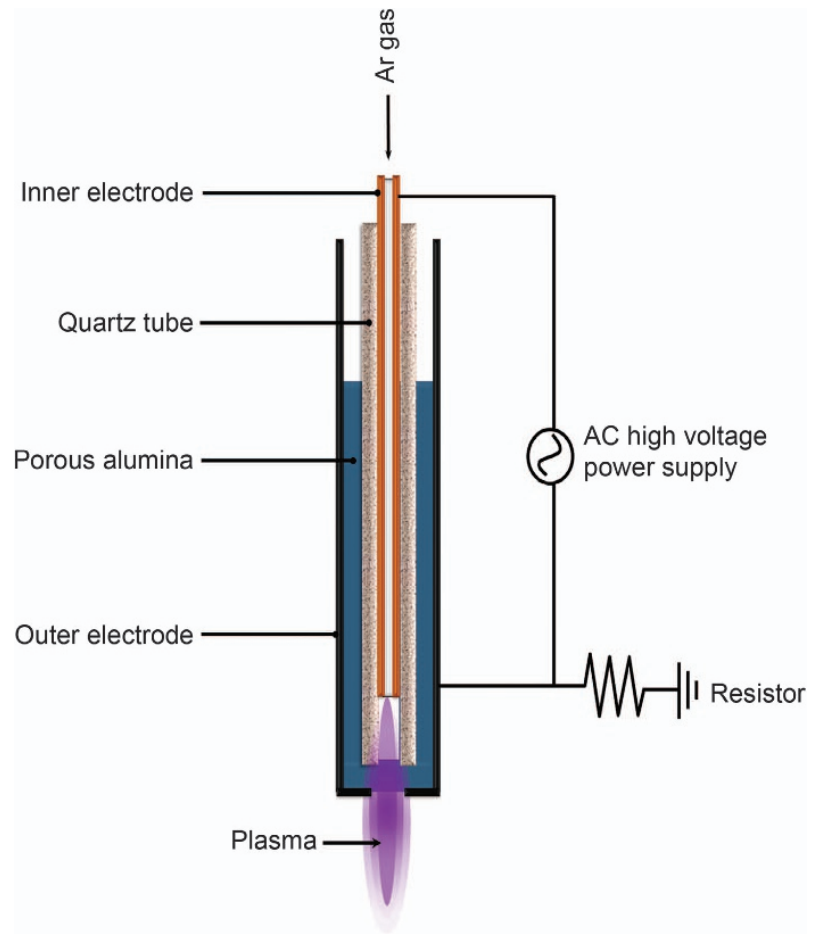

Figure $1 \mathrm{~A}$ schematic diagram of the nonthermal Ar-PJ device. $\mathrm{Ar}$ gas was injected into the inner electrode of the device at a flow rate of 0.5 SLM (standard liters per minute), the alternating current (AC) power supply was operated at $60 \mathrm{~Hz}$, and the input voltage was $100 \mathrm{~V}$. Violet color denotes nonthermal Ar-PJ generated under atmospheric pressure.

can be easily discriminated, i.e., the flat and elongated shape of live cells from the round dead cells. We designed a dielectric barrier discharge (DBD) Ar plasma of a mesh dish type ${ }^{31}$ to expose the Ar plasma to almost all the cells in a $60-\mathrm{mm}$ culture dish at the listed energy amounts (joule, J) (Figure 1 and Table 1). Consistent with previous studies, we also observed that the normal elongated cell morphology changed to a rounded and shrunken shape in the Ar plasma-treated cells: in $\sim 20 \%$ of the cells (after 1 min exposure or $24 \mathrm{~J}$ ), more than $80 \%$ of the cells ( $3 \mathrm{~min}, 72 \mathrm{~J}$ ), and almost $100 \%$ of the cells ( $5 \mathrm{~min}, 120 \mathrm{~J}$ ) (Figure 2a). These morphological changes are characteristic cell death markers, reflecting that Ar plasma induces cell death in 2D monolayer cultures. We also investigated the effects of a jet-type of DBD Ar plasma (Ar-PJ) on 2D monolayer cells (Figure 2b). For this purpose, we treated the MEFs for $30 \mathrm{~s}$ with the nonthermal Ar-PJ used in our previous in vitro assays. ${ }^{20,32}$ Following $24 \mathrm{~h}$ of incubation, MEFs were stained with propidium iodide (PI), which is a red fluorescent dye that is impermeant to intact membranes in live cells but penetrates the damaged membranes of dead cells. All cells within a $1-\mathrm{mm}(1,000-\mu \mathrm{m})$ radius from the contact point of the Ar-PJ (C-zone) exhibited red fluorescence (PI positive), indicating that Ar-PJ also leads to cell death. Extensive death of cancer cells is a requirement for cancer therapy; however, the potentially adverse effects of cell death
Table 1 Energy comparisons between different types of Ar plasma

\begin{tabular}{lcc}
\hline & \multicolumn{2}{c}{ The energy of Ar-plasma (Joule, J) } \\
\cline { 2 - 3 } & \multicolumn{2}{c}{ Type } \\
\cline { 2 - 3 } Time (s) & Mesh dish & Jet \\
\hline 10 & 4 & 69 \\
30 & 12 & 207 \\
60 & 24 & 414 \\
180 & 72 & 1242 \\
300 & 120 & 2070 \\
\hline
\end{tabular}

Abbreviation: Ar, argon.

raise many safety concerns for living organisms, including humans.

Regenerative capacity of the zebrafish caudal fin in response to Ar-PJ: a novel in vivo model for bioplasma safety assessment

To experimentally evaluate the safety of Ar-PJ in living organisms, we selected zebrafish systems, including the zebrafish caudal fin and embryo, which have been widely used as powerful living models for testing the safety of drugs and medical devices before use in specific clinical trials. ${ }^{33,34}$ When we treated the zebrafish with stronger bioplasma than the dosage used for 2D cells, the detrimental effects of bioplasma were observed in the regeneration of the caudal fin of zebrafish: degeneration of the caudal fin (Supplementary Figure 1aa ${ }^{\prime}$ ) or loss of pigment cells in the caudal fin (Supplementary Figure $\left.1 \mathrm{ab}^{\prime}\right)$. In the embryo system, the morphogenesis of blood vessels was abnormally formed in the posterior head region as the bioplasma energy increased (Supplementary Figure 1b). Thus, the highest energy used in Supplementary Figure 1 was excluded, and the Ar-PJ energy of $207 \mathrm{~J}$ (treatment for $30 \mathrm{~s}$ ) (Figure 3) was selected based on the condition that Ar-PJ induces cell death in 2D cell cultures (Figure 2).

Because caudal fin regeneration is normally initiated within one-day post-amputation (dpa), and the epidermis and blastema are regenerated at $4 \mathrm{dpa}$ (Figure 3a), we measured the length of the fin at $4 \mathrm{dpa}$ from the amputation plane to the distal tip as a morphologically measurable indicator (Figures 3b and c, Table 2). ${ }^{35}$ In the untreated and Ar-only-treated groups used as controls, we observed that the amputated fins regenerated to an average length of $0.7 \mathrm{~mm}$, which is typically observed at $4 \mathrm{dpa}$. In the Ar-PJ-treated group, the amputated fins grew back normally to about the same length as those of the controls. This result indicates that Ar-PJ in the dose used in this study does not lead to a detrimental effect on the regeneration of the zebrafish caudal fin.

After amputation or injury, pigment cells, such as melanocytes (melanin-producing black cells) and xanthophore (yellow) cells, are newly formed at approximately $4 \mathrm{dpa}$ and precisely arranged via a cell-to-cell interaction network in the regenerating fin tissues. ${ }^{36,37}$ As such, this precise arrangement 
a Treatment Time (min)

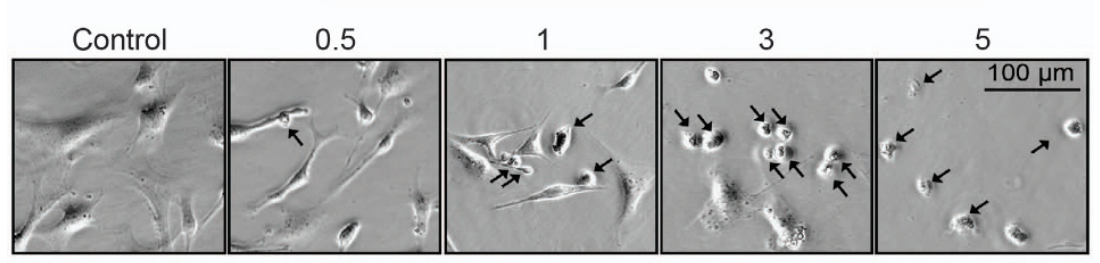

b

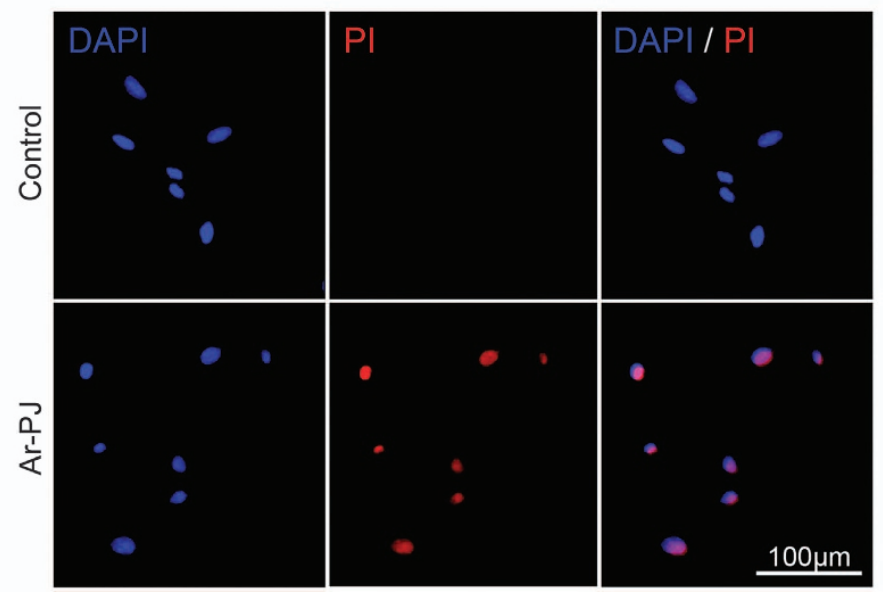

Figure 2 Evaluation of cell death induced by Ar plasma in 2D monolayer cells. (a) Ar plasma (mesh dish-type)-induced cell death. MEFs grown on a 60-mm culture dish were treated with Ar plasma (mesh dish-type) at the indicated times and incubated for an additional $24 \mathrm{~h}$ at $37^{\circ} \mathrm{C}$ in a humidified $5 \% \mathrm{CO}_{2}$ incubator. Cell morphology was photographed in a bright-field mode. Cell shrinkage is a characteristic morphological marker of dead cells (arrows). (b) Ar plasma (jet-type, Ar-PJ)-induced cell death. MEFs grown on a cover glass were placed $10 \mathrm{~mm}$ below the nozzle exit of Ar-PJ and exposed to Ar-PJ for $30 \mathrm{~s}$ (207 J). MEFs were stained with PI and DAPI to identify dead cells (red) and nuclei (blue), respectively.

of pigment cells is widely used as another critical hallmark of zebrafish fin regeneration. After Ar-PJ treatment, we microscopically examined at $4 \mathrm{dpa}$ the pigmentation patterns of the amputated caudal fins to use as a visual color indicator (Figure 3d, Table 2). In the Ar-PJ-treated group, we detected the regenerated melanocytes and xanthophore cells near the amputation plane, which is the same pattern that was found in the control group and extended from the existing pigment cells. This continuously arranged normal pigmentation pattern indicates that Ar-PJ has no destructive effects on the cell-to-cell interaction network and is therefore biologically safe.

Next, we assessed the effect of Ar-PJ on caudal fin regeneration at the molecular level, as the molecular assays are highly sensitive, reliable, and accurate (Figure $3 e$, Table 2). The Wnt/ $\beta$-Catenin signaling pathway has been known to play important roles in promoting cell growth and proliferation in regenerating tissues. ${ }^{38-40}$ Because Wnt8a and $\beta$-Catenin are key effectors of the Wnt $/ \beta$-Catenin signaling pathway, we examined the expression of wntsa mRNA and $\beta$-Catenin protein by whole-mount in situ hybridization (WISH) ${ }^{41}$ and immunohistological staining, respectively (Figure $3 \mathrm{e}$ ). The expression patterns and levels of both genes in the Ar-PJ-treated caudal fins were similar to those in the controls. These results demonstrate that Ar-PJ does not affect tissue regeneration and recovery from injuries in zebrafish used as a living model organism. Therefore, zebrafish caudal-fin regeneration can be used as an effective in vivo model for determining the appropriate dose of Ar-PJ to use in future clinical use and for an Ar-PJ safety assessment.

Development of the zebrafish embryo in response to Ar-PJ: implications for the novel 3D in vivo model for bioplasma safety assessment

Unlike mammalian models, zebrafish undergo external fertilization, and their embryonic development is very fast, taking only $48 \mathrm{~h}$. The developing embryo is also optically transparent, which makes it feasible to non-invasively observe its internal organs and to monitor the embryo at all stages of development (Figure 4a). ${ }^{42,43}$ In addition, zebrafish embryonic development is regulated by the $\mathrm{Wnt} / \beta$-Catenin signaling pathway, ${ }^{44}$ which is a common molecular mechanism that regulates the regeneration of the caudal fin of adult zebrafish. ${ }^{38,45}$ Due to their easy accessibility and excellent advantages, we used zebrafish embryos in our assessment of the in vivo biosafety of Ar-PJ by assessing their developmental capacity. The zebrafish embryo consists of three complex compartments, the cell, yolk, and chorion (Figure 4a). ${ }^{42}$ The distance from the zebrafish embryo center to the chorion is $\sim 0.6 \mathrm{~mm}(600 \mu \mathrm{m})$, which is much shorter than the effective zone $(1000 \mu \mathrm{m})$ of Ar$\mathrm{PJ}$ in the 2D cell culture shown in Figure 2. A single enormous cell $(0 \mathrm{~h}$ post fertilization or hpf) divides repeatedly into thousands of smaller cells at $3.3 \mathrm{hpf}$ and finally develops into 
a

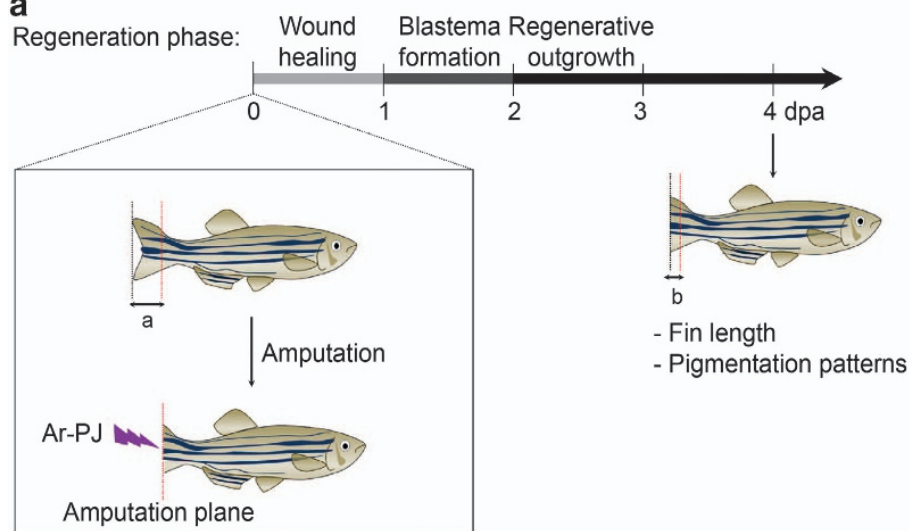

b

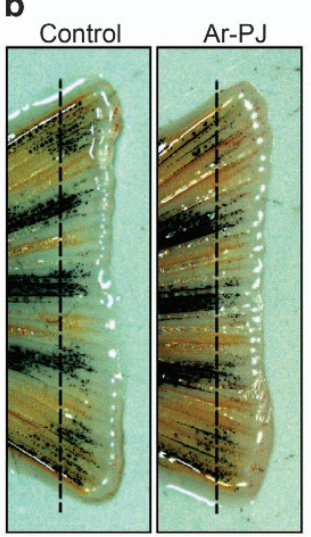

C

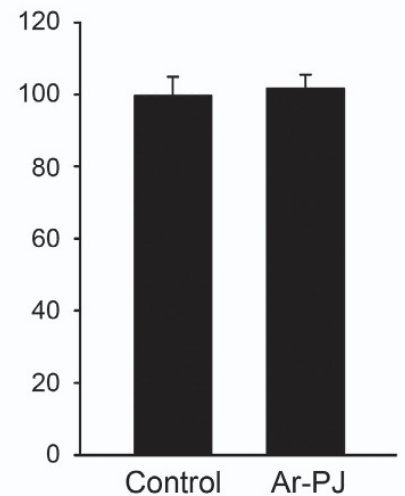

d

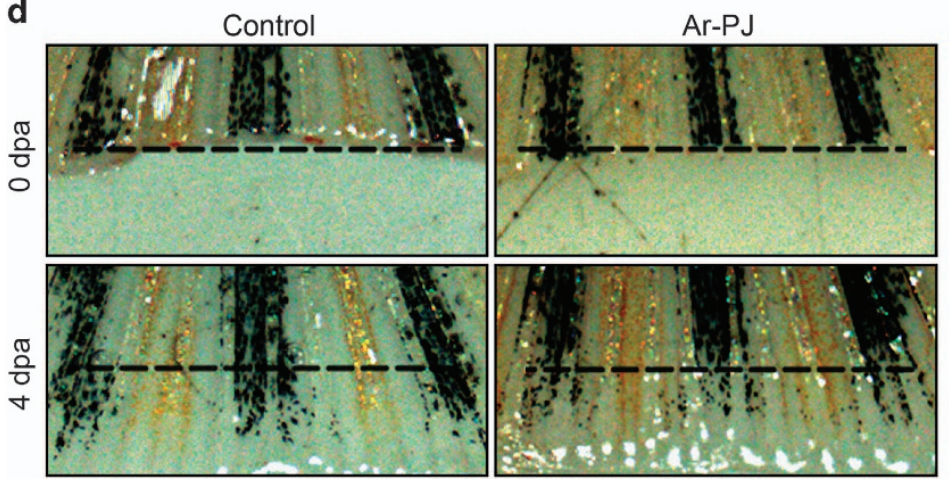

e

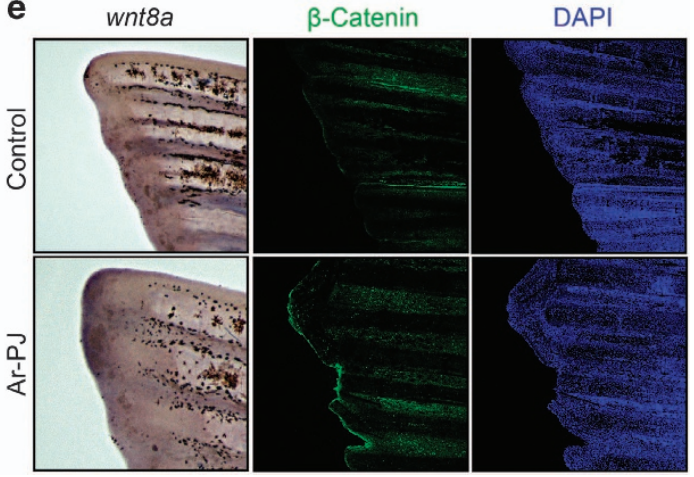

Figure 3 Biosafety of Ar-PJ in living tissues-experimental validation of the regenerative capacity of the zebrafish caudal fin as a novel biosafety assessment system. (a) A schematic timeline of caudal fin regeneration and outline for regeneration experiments. Caudal fins of the zebrafish (aged 3 months) were amputated with a surgical blade and treated with Ar-PJ for $30 \mathrm{~s}$, and the zebrafish were incubated at $33^{\circ} \mathrm{C}$ for the indicated times. ' $a$ ' and ' $b$ ' denote the lengths from the amputation plane to the distal tip of original fin and of the newly forming fin after amputation, respectively. (b) Regrowth rate of the amputated-zebrafish caudal fins, which is a measurable indicator for assessing Ar-PJ biosafety in in vivo tissue networks. Fins processed via the experiments outlined in (a) were photographed at 4 dpa using a MZ FLIII stereomicroscope. (c) Quantification of the regrowth rate. Regrowth was calculated as the ratio of ' $b$ ' relative to ' $a$ '. The ratio of the Ar-PJ treated sample was divided by that of the untreated control, and the values are expressed as a percentage of the control. Data are presented as the mean values \pm s.e.m. $(n=6)$. (d) Expansion patterns of pigment cells in the regenerating fins, a visual indicator of the biosafety of Ar-PJ in cellular networks. Melanocytes (black) and xanthophore cells (yellow) are arranged according to their cell-to-cell interactions. (e) Detection of the regeneration-associated genes, wnt8 and $\beta$-Catenin, in the regenerating fins, molecular indicators of the biosafety of Ar-PJ in living organisms. WISH was performed on zebrafish fins at $4 \mathrm{dpa}$ with a wnt8a probe. Violet color indicates a positive signal of the wnt8a mRNA. Immunofluorescence antibody assay (IFA) was performed on zebrafish fins at 2 dpa with the anti-active- $\beta$-Catenin antibody (green), and nuclei were counterstained with DAPI (blue).

Table 2 List of indicators for the Ar-PJ biosafety assessment

In vivo zebrafish model system

\begin{tabular}{lll} 
Indicator & Caudal fin & Embryo \\
\hline Morphological & Regrowth rate & Lateral length \\
Visual & Pigmented cells & Hatched embryos, \\
& $\begin{array}{l}\text { Blood vessel formation } \\
\text { Mnt8a }\end{array}$ \\
Molecular & $\beta$-Catenin & \\
& &
\end{tabular}

Abbreviation: Ar-PJ, argon plasma jet.

all the organ systems within $48 \mathrm{hpf}$. The yolk provides energy and building blocks during embryonic development (72 hpf). The chorion is a 1.5 - to 2.5 - $\mu \mathrm{m}$-thick cellular envelope that surrounds the embryo and consists of three layers: the outer
(CO, 0.2-0.3 $\mu \mathrm{m}$ thick), middle (CM, 0.3-0.6 $\mu \mathrm{m}$ thick) and inner (CI, $1.0-1.6 \mu \mathrm{m}$ thick) layers. The chorion pore canals (CPCs) are formed in the CM and CI layers, the diameter of the $\mathrm{CPC}$ ranges from 0.5 to $0.7 \mu \mathrm{m}$, and the distance between the centers of the CPCs is $1.5-2 \mu \mathrm{m} .{ }^{46}$ Hence, Ar-PJ components could sufficiently penetrate the chorion and effectively interact with the embryonic cells in living zebrafish embryos.

We chose embryos at $3.3 \mathrm{hpf}$ (blastula period) because critical cellular events, such as cell polarity, cell specification, and axis formation, are initiated during the blastula period of zebrafish embryonic development (Figure 4b). ${ }^{42,47}$ We treated the embryos with Ar-PJ for $30 \mathrm{~s}$, which is the same condition used for the fins and 2D monolayer cultured cells. At $60 \mathrm{hpf}$ (the hatching period), we counted the number of hatched embryos and compared the hatching rates, because hatching is a reliable and easy diagnostic indicator of normal embryogenic 
a

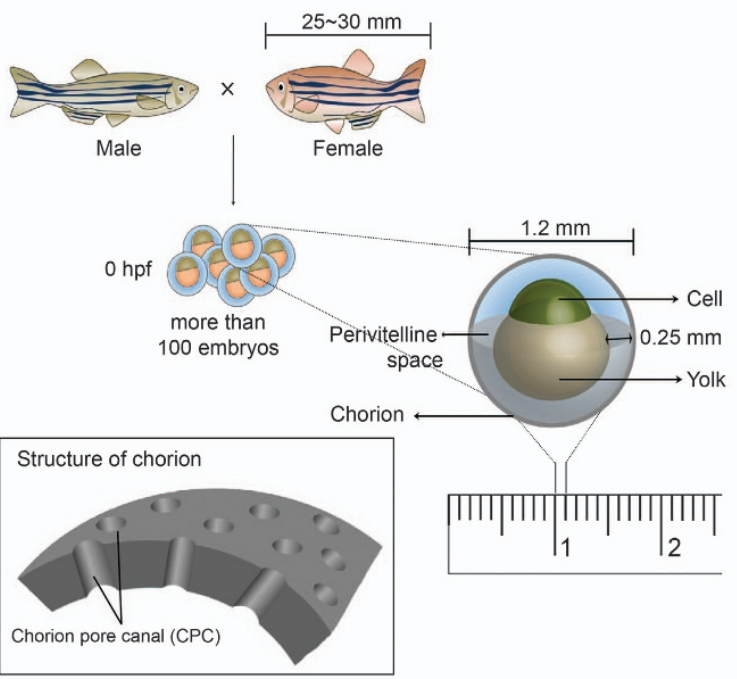

b

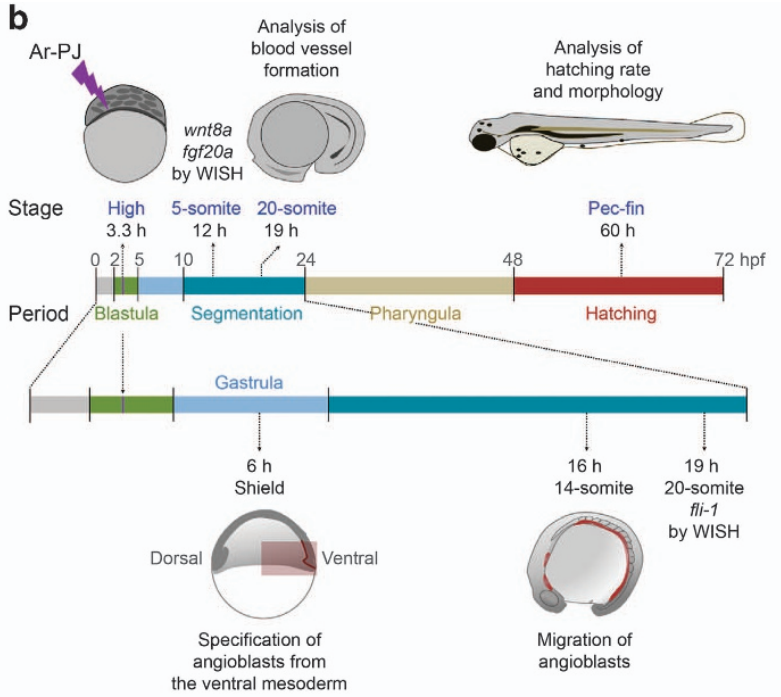

e

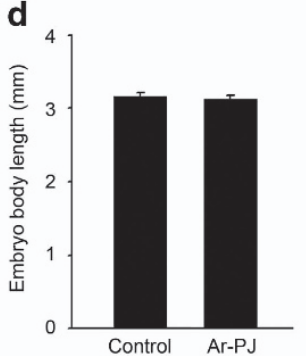

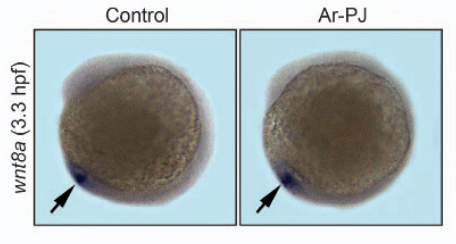

f

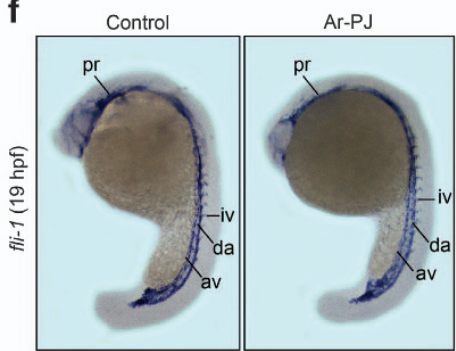

Figure 4 Biosafety of Ar-PJ with respect to the biogenesis of living organisms - experimental validations of embryogenesis as a novel biosafety assessment system. (a) Schematic diagrams of zebrafish fertilization and the structure of an embryo at 0 hpf. (b) A schematic diagram of experimental designs for assessing zebrafish embryogenesis. (c) Evaluation of the completion of embryogenesis in response to Ar-PJ, a visual indicator of Ar-PJ biosafety. Hatched embryos were counted at $60 \mathrm{hpf}$, and the hatching rate was determined by calculating the hatching percentage $(\mathrm{H} \%)$ for each sample: $\mathrm{H} \%=$ (the number of hatched embryos/the total number of embryos) $\times 100$. Lateral view, anterior to the top. (d) Quantification of body length - a measurable indicator of Ar-PJ biosafety assessment. The lateral length of embryos at $60 \mathrm{hpf}$ was measured, and values are presented as the means \pm s.e.m. (control $n=7$, Ar-PJ $n=12$ ). (e) Evaluation of Ar-PJ biosafety at the molecular level. Live zebrafish embryos at the blastula stage (3.3 hpf) were treated for $30 \mathrm{~s}$ with Ar-PJ. WISH was performed with a wnt8a antisense probe on segmentation-period embryos (12 hpf, 5-somite stage). (f) Evaluation of blood vessel morphogenesis, an embryonic visual indicator for Ar-PJ biosafety assessment. WISH was performed with a fli antisense probe on segmentation-period embryos (19 hpf). Vasculogenesis sites are indicated: pharyngeal (pr), dorsal aorta (da), axial vein (av), intersegmental vessels (iv) and intermediate cell mass (icm).

development (Figure 4c, Table 2). During embryonic development, the Ar-PJ-treated embryos exhibited normal morphology with an approximately $85 \%$ hatching rate, similar to those of the Ar-only-treated and untreated control groups. Consistent with the morphology and hatching rate, there was no difference in the lateral length of the embryos (EL) across all three groups, approximately $3.3 \mathrm{~mm}$, which is the recognized EL at $60 \mathrm{hpf}$ (Figure $4 \mathrm{~d}$ ). ${ }^{42}$

To investigate the in vivo biosafety of Ar-PJ at the molecular level, we analyzed the expression level of wnt8a mRNA during the early stage of embryonic development ( $12 \mathrm{hpf}, 5$-somite stage) using WISH (Figure 4e). Consistent with the wnt8a mRNA expression shown in zebrafish caudal fins (Figure 3e), the expression levels and patterns of wnt8a mRNA in the Ar-PJ-treated embryos were equivalent to those observed in the controls. Notably, the formation of new blood vessels, which are mostly composed of endothelial cells, is one of the main aspects of tissue regeneration and embryogenesis and is essential for embryonic survival. ${ }^{48}$ Therefore, to evaluate the effect of Ar-PJ on blood vessel formation during embryogenesis, we treated blastula-period ( $3.3 \mathrm{hpf}$ ) embryos with Ar-PJ for $30 \mathrm{~s}$; at this stage, the cells are not restricted to a specific lineage of endothelial cells (Figure 4f). Endothelial precursor cells (or angioblasts) are specified from the ventral mesoderm during the gastrula period ( $6 \mathrm{hpf}$ ) and then migrate to the embryonic midline, where they develop to approximately the 14-somite stage $(16 \mathrm{hpf})$ before undergoing vasculogenesis. ${ }^{42}$ The vascular ETS transcription factor fli-1 also plays an essential role in endothelial cell development, which indicates that its expression is closely linked to the formation of new blood vessels. ${ }^{49}$ After Ar-PJ treatment, we used WISH to compare the expression level and pattern of the fli-1 mRNA with those in the control groups (Figure 4f). Normally, fli1 expression is detected at the vasculogenesis sites along the axis 
of the whole body, from head to tail..$^{50}$ Consistent with the normal fli-1 expression pattern, we detected a highly positive signal of fli-1 in the Ar-PJ-treated group at the vasculogenesis sites throughout the axis of the whole body from head to tail, including the posterior head region (pharyngeal, pr), the dorsal aorta (da), axial vein (av), intersegmental vessels (iv), and intermediate cell mass (icm). These results reflect no difference in blood vessel formation between the Ar-PJ-treated and control groups at the 20-somite stage of the segmentation period (19 hpf). Collectively, the Ar-PJ-treated embryos exhibited normal embryonic development, and morphology as well as normal expression levels and patterns of the embryonic development marker wnt8a and endothelial marker fli-1. These data demonstrate that Ar-PJ at the dose used in this assay has no impaired effects on embryonic development.

\section{DISCUSSION}

In conclusion, our experimental results using the caudal fin and embryo of the zebrafish demonstrate that Ar-PJ has no adverse effects on fin regeneration and embryogenesis in zebrafish, implying that Ar-PJ does not interrupt the multiple physiological molecular pathways that govern living organisms. Our study has demonstrated that the zebrafish embryogenic developmental system is a rapid and sensitive in vivo assay to assess the biosafety of Ar-PJ and is suitable for determining the appropriate doses of Ar-PJ for medical applications. Therefore, our zebrafish caudal fin regeneration and embryonic development systems can be applied to the evaluation of the in vivo safety of various types of bioplasma sources and can contribute to improving patient safety and the quality of health care.

\section{CONFLICT OF INTEREST}

The authors declare no conflict of interest.

\section{ACKNOWLEDGEMENTS}

This work was supported by the National Research Foundation of Korea (NRF) Grant funded by the Korean Government (MSIP) (NRF-2010-0027963), (NRF-2015M2B2A9031726), (NRF-2016R1A2B4009375), (MEST) (NRF-2014R1A1A2053568) and the financial support of the Catholic Medical Center Research Foundation made in the program year of 2016.

1 Fridman G, Friedman G, Gutsol A, Shekhter AB, Vasilets VN, Fridman A. Applied plasma medicine. Plasma Process Polym 2008; 5: 503-533.

2 Raiser J, Zenker M. Argon plasma coagulation for open surgical and endoscopic applications: state of the art. J Phy D Appl Phys 2006; 39: 3520.

3 Lunov O, Zablotskii V, Churpita O, Chanova E, Sykova E, Dejneka A et al. Cell death induced by ozone and various non-thermal plasmas: therapeutic perspectives and limitations. Sci Rep 2014; 4: 7129.

4 Takamatsu T, Uehara K, Sasaki Y, Miyahara H, Matsumura Y, Iwasawa A et al. Investigation of reactive species using various gas plasmas. RSC Adv 2014; 4: 39901-39905.

5 Schmidt-Bleker A, Winter J, Bösel A, Reuter S, Weltmann K-D. On the plasma chemistry of a cold atmospheric argon plasma jet with shielding gas device. Plasma Sources Sci Technol 2015; 25: 015005.
6 Holmstrom K, Finkel T. Cellular mechanisms and physiological consequences of redox-dependent signalling. Nat Rev Mol Cell Biol 2014; 15: 411-421.

7 Leavy O. Inflammation: regulating ROS. Nat Rev Immunol 2014; 14: 357-357.

8 D'Autréaux B, Toledano MB. ROS as signalling molecules: mechanisms that generate specificity in ROS homeostasis. Nat Rev Mol Cell Biol 2007; 8: 813-824.

9 Tonks NK. Redox redux: revisiting PTPs and the control of cell signaling. Cell 2005; 121: 667-670.

10 Imlay JA, Linn S. DNA damage and oxygen radical toxicity. Science 1988; 240: 1302-1309.

11 Balaban RS, Nemoto S, Finkel T. Mitochondria, oxidants, and aging. Cell 2005; 120: 483-495.

12 Farmer EE, Mueller MJ. ROS-mediated lipid peroxidation and RES-activated signaling. Annu Rev Plant Biol 2013; 64: 429-450.

13 Pero RW, Anderson MW, Doyle GA, Anna CH, Romagna F, Markowitz M et al. Oxidative stress induces DNA damage and inhibits the repair of DNA lesions induced by $\mathrm{N}$-acetoxy-2-acetylaminofluorene in human peripheral mononuclear leukocytes. Cancer Res 1990; 50: 4619-4625.

14 Niethammer P, Grabher C, Look AT, Mitchison TJ. A tissue-scale gradient of hydrogen peroxide mediates rapid wound detection in zebrafish. Nature 2009; 459: 996-999.

15 Nie Q-Y, Ren C-S, Wang D-Z, Zhang J-L. A simple cold Ar plasma jet generated with a floating electrode at atmospheric pressure. App Phys Lett 2008; 93: 011503.

16 Malick KJ. Clinical applications of argon plasma coagulation in endoscopy. Gastroenterol Nurs 2006; 29: 386-391, quiz 392-383.

17 Trachootham D, Alexandre J, Huang P. Targeting cancer cells by ROS-mediated mechanisms: a radical therapeutic approach? Nat Rev Drug Discov 2009; 8: 579-591.

18 Vandamme M, Robert E, Lerondel S, Sarron V, Ries D, Dozias S et al. ROS implication in a new antitumor strategy based on non-thermal plasma. Int J Cancer 2012; 130: 2185-2194.

19 Panngom K, Baik K, Nam M, Han J, Rhim H, Choi E. Preferential killing of human lung cancer cell lines with mitochondrial dysfunction by nonthermal dielectric barrier discharge plasma. Cell Death Dis 2013; 4: e642.

20 Han J-H, Nam M-K, Kim Y-H, Park D-W, Choi EH, Rhim H. Effects of argon-plasma jet on the cytoskeleton of fibroblasts: implications of a new approach for cancer therapy. KSBB J 2012; 27: 308-312.

21 Utsumi F, Kajiyama H, Nakamura K, Tanaka H, Mizuno M, Toyokuni S et al. Variable susceptibility of ovarian cancer cells to non-thermal plasma-activated medium. Oncol Rep 2016; 35: 3169-3177.

22 Sakurai T, He G, Matsuzawa A, Yu G-Y, Maeda S, Hardiman G et al. Hepatocyte necrosis induced by oxidative stress and IL-1 $\alpha$ release mediate carcinogen-induced compensatory proliferation and liver tumorigenesis. Cancer cell 2008; 14: 156-165.

23 Rock KL, Kono H. The inflammatory response to cell death. Annu Rev Pathol 2008; 3: 99-126.

24 Spirig C, Omlin A, D'Addario G, Loske K-D, Esenwein P, Geismar JH et al. Radiation recall dermatitis with soft tissue necrosis following pemetrexed therapy: a case report. J Med Case Rep 2009; 3: 93.

25 Huang J, Li H, Chen W, Lv G-H, Wang X-Q, Zhang G-P et al. Dielectric barrier discharge plasma in Ar/O2 promoting apoptosis behavior in A549 cancer cells. Appl Phys Lett 2011; 99: 253701.

26 Zhang X, Li M, Zhou R, Feng K, Yang S. Ablation of liver cancer cells in vitro by a plasma needle. Appl Phys Lett 2008; 93: 021502.

27 Zon LI. Intrinsic and extrinsic control of haematopoietic stem-cell self-renewal. Nature 2008; 453: 306-313.

28 Stoick-Cooper CL, Weidinger G, Riehle KJ, Hubbert C, Major MB, Fausto N et al. Distinct Wnt signaling pathways have opposing roles in appendage regeneration. Development 2007; 134: 479-489.

29 Whitehead GG, Makino S, Lien C-L, Keating MT. fgf20 is essential for initiating zebrafish fin regeneration. Science 2005; 310: 1957-1960.

30 Joh HM, Kim SJ, Chung T, Leem S. Comparison of the characteristics of atmospheric pressure plasma jets using different working gases and applications to plasma-cancer cell interactions. AIP Adv 2013; 3: 092128.

31 Park JH, Kumar N, Park DH, Yusupov M, Neyts EC, Verlackt CC et al. A comparative study for the inactivation of multidrug resistance bacteria using dielectric barrier discharge and nano-second pulsed plasma. Sci Rep 2015; 5: 13849 . 
32 Hong YC, Kang WS, Hong YB, Yi WJ, Uhm HS. Atmospheric pressure air-plasma jet evolved from microdischarges: eradication of $E$. coli with the jet. Phys Plasmas 2009; 16: 123502.

33 Kanungo J, Cuevas E, Ali SF, Paule MG. Zebrafish model in drug safety assessment. Curr Pharm Design 2014; 20: 5416-5429.

34 MacRae CA, Peterson RT. Zebrafish as tools for drug discovery. Nat Rev Drug Discov 2015; 14: 721-731.

35 lovine MK. Conserved mechanisms regulate outgrowth in zebrafish fins. Nat Chem Biol 2007; 3: 613-618.

36 Patterson LB, Bain EJ, Parichy DM. Pigment cell interactions and differential xanthophore recruitment underlying zebrafish stripe reiteration and Danio pattern evolution. Nat Commun 2014; 5: 5299.

37 Singh AP, Nüsslein-Volhard C. Zebrafish stripes as a model for vertebrate colour pattern formation. Curr Biol 2015; 25: R81-R92.

38 Wehner D, Cizelsky W, Vasudevaro MD, Özhan G, Haase C, KagermeierSchenk $B$ et al. Wnt/ $\beta$-catenin signaling defines organizing centers that orchestrate growth and differentiation of the regenerating zebrafish caudal fin. Cell Rep 2014; 6: 467-481.

39 van de Wetering M, de Lau W, Clevers H. WNT signaling and lymphocyte development. Cell 2002; 109: S13-S19.

40 Wehner D, Weidinger G. Signaling networks organizing regenerative growth of the zebrafish fin. Trends Genet 2015; 31: 336-343.

41 Kim G-Y, Kim H-Y, Kim H-T, Moon J-M, Kim C-H, Kang S et al. HtrA1 is a novel antagonist controlling fibroblast growth factor (FGF) signaling via cleavage of FGF8. Mol Cell Biol 2012; 32: 4482-4492.

42 Kimmel CB, Ballard WW, Kimmel SR, Ullmann B, Schilling TF. Stages of embryonic development of the zebrafish. Dev Dyn 1995; 203: 253-310.

43 Pantazis $P$, Supatto W. Advances in whole-embryo imaging: a quantitative transition is underway. Nat Rev Mol Cell Biol 2014; 15: 327-339.

44 Peifer M, Polakis P. Wnt signaling in oncogenesis and embryogenesis-a look outside the nucleus. Science 2000; 287: 1606-1609.

45 Lewis J. From signals to patterns: space, time, and mathematics in developmental biology. Science 2008; 322: 399-403.
46 Rawson DM, Zhang T, Kalicharan D, Jongebloed WL. Field emission scanning electron microscopy and transmission electron microscopy studies of the chorion, plasma membrane and syncytial layers of the gastrula-stage embryo of the zebrafish Brachydanio rerio: a consideration of the structural and functional relationships with respect to cryoprotectant penetration. Aquacult Res 2000; 31: 325-336.

47 Keller PJ, Schmidt AD, Wittbrodt J, Stelzer EH. Reconstruction of zebrafish early embryonic development by scanned light sheet microscopy. Science 2008; 322: 1065-1069.

48 Chávez MN, Aedo G, Fierro FA, Allende ML, Egaña JT. Zebrafish as an emerging model organism to study angiogenesis in development and regeneration. Front Physiol 2016; 7: 56.

49 Ben-David Y, Giddens E, Letwin K, Bernstein A. Erythroleukemia induction by Friend murine leukemia virus: insertional activation of a new member of the ets gene family, Fli-1, closely linked to c-ets-1. Gene Dev 1991; 5: 908-918.

50 Brown LA, Rodaway AR, Schilling TF, Jowett T, Ingham PW, Patient RK et al. Insights into early vasculogenesis revealed by expression of the ETS-domain transcription factor Fli-1 in wild-type and mutant zebrafish embryos. Mech Dev 2000; 90: 237-252.

This work is licensed under a Creative Commons Attribution-NonCommercial-NoDerivs 4.0 International License. The images or other third party material in this article are included in the article's Creative Commons license, unless indicated otherwise in the credit line; if the material is not included under the Creative Commons license, users will need to obtain permission from the license holder to reproduce the material. To view a copy of this license, visit http://creativecommons.org/licenses/by-nc-nd/4.0/

Supplementary Information accompanies the paper on Experimental \& Molecular Medicine website (http://www.nature.com/emm) 